\title{
Clinical highlights from Amsterdam
}

\author{
Jouke T. Annema ${ }^{1}$, Ioannis Vogiatzis ${ }^{2,3}$, Aleksander Grgic ${ }^{4,5}$, Katerina Antoniou ${ }^{6}$, \\ Björn Ställberg ${ }^{7}$ and Felix F. Herth ${ }^{8}$
}

\section{Affiliations:}

${ }^{1}$ Dept of Respiratory Medicine, Academic Medical Center, University of Amsterdam, Amsterdam, The Netherlands.

${ }^{2} 1$ st Dept of Respiratory Medicine, Pulmonary Rehabilitation Unit, National and Kapodistrian University of Athens, Athens, Greece.

${ }^{3}$ Dept of Physical Education and Sports Sciences, National and Kapodistrian University of Athens, Athens, Greece.

${ }^{4}$ Dept of Nuclear Medicine, Saarland University Medical Center, Homburg, Germany.

${ }^{5}$ Radiological Practice Homburg, Germany.

${ }^{6}$ Dept of Thoracic Medicine, Medical School, University of Crete, Heraklion, Greece.

${ }^{7}$ Dept of Public Health and Caring Sciences, Family Medicine and Preventive Medicine, Uppsala University, Uppsala, Sweden.

${ }^{8}$ Dept of Pneumology and Critical Care Medicine, Thoraxklinik University of Heidelberg, Heidelberg, Germany.

Correspondence: Jouke T. Annema, Dept of Respiratory Medicine, G5-247, Academic Medical Centre, University of Amsterdam, P.O. Box 22700, NL-1100 DE Amsterdam, The Netherlands. E-mail: j.t.annemadamc.nl

ABSTRACT This article contains highlights and a selection of the scientific advances from the Clinical Assembly that were presented at the 2015 European Respiratory Society International Congress in Amsterdam, the Netherlands. The most relevant topics for clinicians will be discussed, covering a wide range of areas including interventional pulmonology, rehabilitation and chronic care, thoracic imaging, diffuse and parenchymal lung diseases, and general practice and primary care. In this comprehensive review, exciting novel data will be discussed and put into perspective.

@ERSpublications

This article discusses advancements in clinical pulmonary medicine presented at the 2015 ERS Congress http://ow.ly/OXOI3010yN9

Received: March 042016 | Accepted after revision: May 222016

Conflict of interest: Disclosures can be found alongside this article at openres.ersjournals.com

Copyright $\odot$ ERS 2016. This article is open access and distributed under the terms of the Creative Commons Attribution Non-Commercial Licence 4.0. 


\section{Introduction}

The 2015 European Respiratory Society (ERS) International Congress in Amsterdam (the Netherlands) was the largest ERS congress ever with an attendance of over 23000 participants. 5421 abstracts were submitted of which 4021 were accepted (acceptance rate 74\%); the majority focusing on clinical problems. For the Clinical Assembly, 886 (73\%) of the 1209 submitted abstracts were accepted. All abstracts were scored by multiple independent reviewers who were unaware of the authors and their institutions. Oral presentations were rewarded to those abstracts with the highest scores. In addition to oral and poster presentation/discussion sessions, state-of-the-art lectures and grand rounds were given by international experts. This article discusses key items from various fields of clinical pulmonary medicine.

\section{Pulmonary rehabilitation}

Important advances have been achieved in optimising the effectiveness of pulmonary rehabilitation in patients with co-existing chronic obstructive pulmonary disease (COPD) and chronic heart failure (CHF), idiopathic pulmonary fibrosis (IPF) and pulmonary arterial hypertension. Furthermore, there is emerging evidence that comprehensive home care programmes can reduce the rate of exacerbations and hospital admissions. Reversing physical inactivity via tele-coaching and tele-rehabilitation regimes increasingly appears to be a feasible alternative to outpatient pulmonary rehabilitation programmes.

Along these lines, CHowdhury et al. [1] provided evidence that completion rates and responses to pulmonary rehabilitation are not influenced by co-existing COPD and CHF. LAVENEZIANA et al. [2] demonstrated that without any changes in resting or exercise haemodynamics, a 12-week exercise training-related rehabilitation programme was sufficient to reduce the ventilatory requirement and intensity of exertional dyspnoea during exercise in patients with idiopathic pulmonary arterial hypertension. A 12-week exercise rehabilitation programme was shown to be effective in terms of enhancing functional capacity in patients with IPF [3].

In a randomised controlled trial (RCT), Ko et al. [4] implemented a comprehensive, individualised care plan which included optimisation of medication, nurse-led education, physiotherapist support for pulmonary rehabilitation, monthly telephone calls by a respiratory nurse for a period of 1 year, and follow-up at a respiratory clinic by a respiratory specialist once every 3 months for 1 year in 90 patients with COPD. The results of the RCT revealed that hospital readmissions ( $1.56 \pm 2.13$ versus $2.38 \pm 2.14$ visits) as well as length of stay (7.41 \pm 11.29 versus $12.21 \pm 12.87$ days) were reduced, whilst symptoms (modified Medical Research Council $-0.1 \pm 0.7$ versus $0.2 \pm 0.6)$ and quality of life score $(-8.5 \pm 16.6$ versus $-0.1 \pm 15.7)$ were meaningfully improved. Furthermore, in another RCT study (REVIVE), exercise rehabilitation initiated after discharge from hospital following critical illness demonstrated significant improvements in functional outcomes and self-efficacy [5].

Use of modern technology facilitates remote implementation of pulmonary rehabilitation and physical activity promotion programmes. Tele-rehabilitation is a promising strategy to improve access and adherence to rehabilitation. In the study by VAsilopoulou et al. [6] home tele-rehabilitation was shown to be equally effective to hospital-based maintenance rehabilitation in preserving the initial benefits acquired during an initial outpatient pulmonary rehabilitation programme in the long term. The study by COATs et al. [7] investigated the feasibility and usability of a home-based tele-rehabilitation real-time monitoring and interactive exercise programme in lung cancer patients receiving chemotherapy and provided evidence of positive effects on patients' functional capacity.

Low physical activity levels constitute the strongest predictor of mortality in COPD. ADAMI et al. [8] showed that low muscle oxidative capacity is an independent predictor of inactivity in COPD, thereby suggesting that therapies to target pulmonary and peripheral COPD pathologies are necessary to increase physical activity and quality of life, and reduce comorbidities and mortality. Along these lines, bronchoscopic lung volume reduction using endobronchial valves was shown to be a promising treatment for patients with severe emphysema as it significantly improved daily physical activity levels and movement intensity in patients with severe emphysema [9]. A European multi-centre RCT (PROACTIVE) revealed that physical activity can be significantly increased in patients with COPD using a step counter and a smartphone-based semi-automated tele-coaching programme [10].

\section{Chest imaging}

During the 2015 ERS International Congress some interesting data concerning new promising imaging techniques, as well as deeper insights in to the already established techniques, were presented.

One of the emphases of presented abstracts dealt with COPD and emphysema. GALBAN et al. [11] presented data from the COPD Gene study, which evaluated parametric response imaging on a data set of 4832 patients. Parametric response imaging measures for both small airways disease and emphysema were independently associated with the St George's Respiratory Questionnaire, BODE index (body mass index, 
airflow obstruction, dyspnoea and exercise capacity) and severe exacerbations [11], providing an opportunity to understand the impact of structural abnormalities on clinical disease severity in COPD.

A greater degree of airway wall thickness is associated with worse lung function in COPD patients. POMPE et al. [12] examined reproducibility of airway wall thickness measurements in a lung cancer screening setting in a data set of 591 men. They showed that airway wall thickness quantified on computed tomography (CT) and expressed as Pi10 (square root of wall area of a 10-mm lumen perimeter) has good reproducibility. An increase in Pi10 of at least $1.22 \mathrm{~mm}$ is required for detection of an increase in the extent of airway wall thickness. For the airway wall thickness measurements, anatomical labelling in the human airway tree is well defined up to the segmental level; however, assignments of subsegmental level are not well defined. TsChirRen et al. [13] developed a reliable method to include subsegmental branches in an automated fashion, which may provide the opportunity to study the spatial dependence of airway phenotypes.

Osteoporosis is associated with COPD and smoking. POMPE et al. [14] examined whether COPD-related measures on CT were associated with lower bone density in a cohort of 1093 male patients from the NELSON lung cancer trial. They concluded that bone density is lower with increasing extent of emphysema and small airways disease, but is not associated with large airway disease or tracheal deformity. Thus, this may indicate the necessity to measure bone density early in the disease course in order to prevent vertebral fractures.

Another main focus was imaging of pulmonary hypertension. SCHÖENFELD et al. [15] demonstrated improvement of cardiac output and pulmonary blood flow in 22 patients with chronic thromboembolic pulmonary hypertension (CTEPH) after pulmonary endarterectomy by magnetic resonance imaging (MRI). EMA et al. [16] retrospectively investigated a cohort of 60 inoperable patients with CTEPH, who were medically treated. They concluded that the increased ratio between pulmonary artery and ascending aorta, as well as between right and left ventricle, were associated with poor outcome [16]. BAKKER et al. [17] explored the influence of high lung density on the pulmonary artery diameter in patients with systemic sclerosis and compared these with healthy subjects and emphysema patients. The presence of interstitial lung disease (ILD) predicted pulmonary artery diameter in patients with systemic sclerosis, indicating a possible relationship between these two parameters that may cause pulmonary hypertension [17].

A few more innovative abstracts focussed at the level of alveolar microstructures. BRochHAUSEN et al. [18] demonstrated differences in airway measurements between frozen and paraffin sections of porcine lungs by histological CT, as well as micro-CT examinations. In another study by VANDE VeLDE et al. [19] different lung biomarkers in free-breathing mice underwent several longitudinal micro-CT examinations after induction of bleomycin-induced fibrosis, aspergillosis and cryptococcosis were evaluated. The importance of quantifying total lung volume in addition to aerated lung or lesion volume was stressed. In future this may improve translatability of therapy from mice to men.

Finally, CHAN et al. [20] evaluated 23 asthmatics with CT densitometry and ${ }^{3} \mathrm{He}$ diffusion MRI, evaluating mean lung density and estimates of mean alveolar dimension. They found statistically significant correlations for each of the four lobar regions [20].

\section{Interventional pulmonology}

In recent years, several technological advancements have emerged for both diagnostic and therapeutic purposes for a variety of diseases such as emphysema, difficult-to-treat asthma, lung cancer and ILDs. Some technologies have been incorporated into recent guidelines whereas the position of others is still under investigation. The value of transbronchial cryobiopies will be discussed in the Interstitial lung diseases section. The advances in endoscopic treatments for obstructive lung disease will be presented in the COPD and asthma section.

\section{Lung cancer}

Current guidelines advocate endosonography as the diagnostic test of choice for mediastinal nodal tissue staging. Data from a prospective international trial $(n=229)$ show that inserting the endobronchial ultrasound (EBUS) scope into the oesophagus (endoscopic ultrasound using the EBUS scope: EUS-B) following a complete EBUS examination results in the detection of additional mediastinal metastases in $7 \%$ of patients [21]. In the ERS/European Society of Thoracic Surgeons/European Society of Gastrointestinal Endoscopy guidelines on lung cancer staging, the combined use of EBUS and EUS-B is advocated [22]. The optimal sedation strategy for EBUS is an ongoing topic of discussion. In the SEDATE study, which evaluated 133 patients undergoing EBUS, patients sedated with propafol \pm remifentanyl reported less discomfort, recall of the procedure and tendency to vomit versus those sedated with midazolam \pm fentanyl. Operator satisfaction was also improved [23]. Besides endosonography, there is increasing interest in the use of transthoracic ultrasound for the diagnosis of lung cancer. To date, transthoracic ultrasound is still underused by pulmonary clinicians. In a retrospective study using transthoracic ultrasound as a guiding tool for lung 
$(n=107)$ and pleura $(n=19)$ biopsies, respiratory physicians obtained a diagnostic yield of $79 \%$ in those diagnosed with lung cancer [24].

\section{Interstitial lung diseases}

ILDs increasingly get attention due to the clinical availability of antifibrotic drugs. Additionally, evidence shows that cryobiopsies of the lung parenchyma taken during bronchoscopy are frequently a minimal alternative for surgical lung biopsies in helping to diagnose specific ILD entities.

\section{Idiopathic pulmonary fibrosis}

The recent official American Thoracic Society/ERS/Japanese Respiratory Society/Latin American Thoracic Society statement has confirmed the change in the landscape of IPF. The completion of three successful RCTs has led to the licensing of two novel drugs, namely pirfenidone and nintedanib in Europe, the USA and Japan. Both drugs are effective in slowing functional decline in IPF and are now officially, although conditionally, recommended for the treatment of this dreadful disease [25].

Novel data and real life experience regarding the use of the pirfenidone and nintedanib were presented during the ERS International Congress [26-28]. Pirfenidone, in a real-world setting, was generally safe and well-tolerated, while patient characteristics and adverse reactions were similar in the three largest enrolling countries [26]. Nintedanib showed long-term efficacy and safety in an interim analysis from the IMPULSIS-ON extension trial [27]. Data regarding the use of these drugs in advanced disease are awaited. Although acute exacerbations in IPF are clinically defined as noninfectious, occult bacterial or viral infections may be involved [29]. Molyneaux et al. [30] characterised the changes in the respiratory microbiome during acute exacerbations of IPF, and observed an increased bronchoalveolar lavage bacterial burden in acute exacerbations when compared to stable disease, with an increase in the percentage of proteobacteria populations.

\section{Idiopathic interstitial pneumonia}

The diagnosis of idiopathic interstitial pneumonias (IIPs) requires the exclusion of other causes, such as collagen tissue disorders (CTDs). In clinical practice there are patients with IIPs and features (clinical/ serological/morphological) that increase the likelihood of an underlying CTD, but not enough features to confirm the diagnosis of a specific CTD. The ERS/American Thoracic Society Task Force has proposed the umbrella term of "interstitial pneumonia with autoimmune features" for patients with IIPs and signs of an autoimmune disease. The diagnosis requires the patient to fulfil the a priori criteria plus one or more features of at least two out of three domains (clinic/serology/morphology). It should be stressed though that this is not a guideline document and the purpose is only to suggest the possibility to treat these patients as having an underlying immune dysregulation (although the final decision is still left to the individual healthcare provider) and to provide input for further studies including patients with more or less identical characteristics [31]. Data regarding the patients with lung dominant disease has been recently presented [32].

\section{Diagnosing ILDs}

The diagnosis of a specific ILD is commonly made in a multidisciplinary setting by a respiratory physician, pathologist and radiologist. Transbronchial cryobiopsy is a novel bronchoscopy-based technique for tissue acquisition of the alveolar compartment and a less invasive alternative for surgical lung biopsy. In a large $(n=312)$ prospective study in transplant and ILD patients, a specific diagnosis was obtained in $85 \%$ of cases. Bleeding complications occurred in $27 \%$ of procedures (severe in $5 \%$ ) and pneumothorax occurred in $8 \%$, requiring chest tube drainage in 3\% [33]. Lopez et al. [34] found a 23\% complication rate (pneumothorax and bleeding) following cryobiopsy for ILD diagnostics in 54 patients.

\section{COPD and asthma}

General practice and primary care

In the field of general practice and primary care some interesting data were presented dealing with the diagnosis and management of COPD.

A cluster RCT by BoLAND et al. [35] assessed the association between registration of performance indicators of COPD care and improvement in health outcomes. The study showed that process indicators of the quality of COPD care were weakly associated with improved health outcomes.

COPD readmissions and associated factors were evaluated in a retrospective longitudinal study of all COPD patients registered at general practices in London (UK) and admitted as an emergency with COPD (2006-2010), and not having a COPD admission in the preceding 12 months [36]. 38504 admissions to 41 hospitals of 22462 patients from 1632 general practices were included. One-third of the patients had at least one readmission over the 4 years and $8 \%$ of the patients were readmitted within 28 days of discharge. 
The risk of readmission was not associated with general practice performance or with admitting hospital. The authors concluded that the rate of COPD readmission has limited value as a marker of care quality.

JORDAN et al. [37] presented data from a pragmatic RCT of targeted case findings for COPD versus routine practice in primary care. They found that a targeted case-finding programme was significantly more effective in identifying new cases of COPD than routine care. An approach combining postal and opportunistic questionnaires followed by spirometry among those reporting relevant symptoms was more than twice as effective as an opportunistic only approach.

The effectiveness of a physical exercise training programme in patients with mild-to-moderate COPD (forced expiratory volume in $1 \mathrm{~s}$ (FEV1) $74.2 \%$ pred) was studied in a RCT in primary care [38]. The patients participated in a 4-month physical exercise training programme or usual care. The programme was effective in improving exercise capacity and parts of muscle force but there were no differences between groups in daily physical activity or in quality of life.

Buni et al. [39] assessed the magnitude of COPD over diagnosis in a COPD cohort with 1473 general practitioner-diagnosed COPD patients from primary care in the UK. Based on the 2004 Global Initiative for Chronic Obstructive Lung Disease, LLN (GLI-2012 equations) and the National Institute for Health and Clinical Excellence definitions, $13.7 \%, 28.1 \%$ and $32.3 \%$ of participants were potentially over diagnosed with COPD, respectively. They identified female sex, obesity, restrictive lung pattern and multiple comorbidities as potential predictors for COPD over-diagnosis.

JosEPHS et al. [40] presented data on smoking status from a retrospective observational study in a large cohort of COPD patients in a UK general practice population. The proportion of current smokers in patients with an $\mathrm{FEV}_{1}<50 \%$ was highest among the youngest patients. The authors concluded that smoking cessation has been largely unsuccessful in younger patients with better preserved lung function who have the greatest scope for improving their prognosis.

In a study from Sweden, ROMBERG et al. [41] reported the effect of certification of asthma/COPD clinics in primary healthcare according to the Swedish national criteria for asthma/COPD clinics. By certifying asthma/ COPD clinics, both the education level of the nurses and the allocated time for patients was increased.

Finally, in a study from Spain the authors evaluated the prevalence of comorbidities in patients with asthma-COPD overlap syndrome (ACOS) in primary care in comparison with patients with COPD [42]. From the MAJORICA database of primary care in Spain they identified 5093 ACOS patients and compared them with 22778 COPD patients. Patients with COPD were older (COPD 65.8 years; ACOS 64.0 years) and differed by nonsmoking status (COPD 22\%; ACOS 46\%). In the population of ACOS patients, allergic rhinitis, anxiety, gastro-oesophageal reflux disease and osteoporosis were more prevalent than in COPD patients, while ischaemic heart disease and chronic kidney disease were less frequent.

\section{Endoscopic procedures for emphysema/COPD}

Although the concept of endobronchial valve treatment is well described, data on which patients would benefit best are still lacking. KLOOSTER and co-workers $[43,44]$ showed in a randomised design $(\mathrm{n}=84)$ that endobronchial valve treatment versus standard medical care was highly effective when treating severe emphysema patients without collateral ventilation. FEV1 increased by $22.7 \%$, forced vital capacity by $442 \mathrm{~mL}$ and 6-min walking distance (6MWD) by $106 \mathrm{~m}$ at the cost of a $18 \%$ pneumothorax rate. Similar outcomes were found in a small $(\mathrm{n}=19)$ prospective study by VALIPOUR et al. [45] who also selected patients with heterogeneous emphysema and complete lobar fissures. These studies are expected to be of major importance for getting valves into guidelines.

Another concept of endobronchial volume reduction is endobronchial coil placement. In a retrospective analysis of 68 patients, the Heidelberg group showed that coil placement in severe emphysema patients resulted in significant improvements in FEV1, vital capacity, residual volume and 6MWD at 90 days. However, the complication rate was $66 \%$ and two patients died [46].

Lung volume reduction can also be achieved by treating diseased airways segments with steam. In the STEP-UP randomised trial, bronchoscopic application of thermal vapour of the most affected emphysema areas versus optimal medical management showed improvements in FEV1 (+13\%), St George's Respiratory Questionnaire $(11.1)$ and 6MWD $(+31 \mathrm{~m})$ with an acceptable exacerbation and pneumonia rate [47].

A novel bronchoscopic concept to treat severe COPD was presented by SLEBOS et al. [48] and reported how they had used targeted lung denervation therapy to ablate the parasympathetic nerves along the main bronchi. 2 years of safety data of a prospective trial in 22 patients showed an acceptable adverse event rate, mostly consisting of COPD exacerbations. KoELENBERG et al. [49] showed that in these patients targeted lung 
denervation therapy has an additive bronchodilating effect to ipratropium in the 20 Watt group ( $\mathrm{p}=0.047$ at 365 days).

\section{Thermoplasty}

Bronchial thermoplasty is increasingly used in selected patients with difficult-to-treat asthma. However, the mechanism of action is still poorly understood. Thermoplasty aims to reduce airway smooth muscle. There is increasing interest to the effect of thermoplasty on airway innervation. Bronchial biopsies before and after bronchial thermoplasty showed a significant reduction of nerve C-fibres and an increase in neutrophils and mononuclear cell in filtration in the bronchial mucosa [50].

\section{References}

1 Kaliaraju PD, Nolan MC, Canavan LJ, et al. Comorbidity burden and the effect on completion rates and response to pulmonary rehabilitation (PR) in COPD. Eur Respir J 2015; 46: Suppl. 59, PA741.

2 Laveneziana P, Degano B, Boutet K, et al. Effects of 12-week exercise training-related rehabilitation on exertional dyspnoea in patients with idiopathic pulmonary arterial hypertension. Eur Respir J 2015; 46: Suppl. 59 , PA2230.

3 Vainshelboim B, Oliveira J, Fox B, et al. Physical activity following 12-week supervised exercise training program in patients with idiopathic pulmonary fibrosis. Eur Respir J 2015; 46: Suppl. 59, OA1754.

4 Ko WSF, Cheung N-K, Rainer T, et al. Comprehensive care programme for patients with chronic obstructive pulmonary disease (COPD) - a randomized controlled trial (RCT). Eur Respir J 2015; 46: Suppl. 59 , OA272.

5 McDowell K, O'Neill B, Blackwood B, et al. The REVIVE study: a randomised controlled trial of the effect of a programme of exercise on physical function in survivors of critical illness after discharge from the intensive care unit. Eur Respir J 2015; 46: Suppl. 59, OA274.

6 Vasilopoulou M, Papaioannou IA, Chynkiamis N, et al. Effectiveness of home tele-rehabilitation on functional capacity and daily physical activity in COPD patients. Eur Respir J 2015; 46: Suppl. 59, OA273.

7 Coats V, Moffet H, Simard S, et al. Home-based telerehabilitation program using real-time monitoring and interactive exercise for patient with lung cancer: a feasibility study. Eur Respir J 2015; 46: Suppl. 59, OA3283.

8 Adami A, Cao R, Porszasz J, et al. Skeletal muscle oxidative capacity is an independent predictor of physical activity in smokers with and without COPD. Eur Respir J 2015; 46: Suppl. 59, OA1985.

9 Hartman EJ, Klooster K, Slebos D-J, et al. Daily physical activity significantly improves after endobronchial valve treatment in patients with emphysema. Eur Respir J 2015; 46: Suppl. 59, OA1767.

10 Demeyer $\mathrm{H}$, Louvaris Z, Tanner R, et al. Increasing physical activity in patients with COPD using a telecoaching program: a multicenter RCT. Eur Respir J 2015; 46: Suppl. 59, OA278.

11 Galban C, Chamberlain R, Hoff B, et al. Parametric response mapping of COPD phenotypes: a COPDGene study. Eur Respir J 2015; 46: Suppl. 59, OA4985.

12 Pompe E, Schmidt M, Van Rikxoort E, et al. Reproducibility of airway wall thickness measurements on CT in a lung cancer screening setting. Eur Respir J 2015; 46: Suppl. 59, PA762.

13 Tschirren J, Vidal C, Baron B, et al. Fully automated labeling of sub-segmental airways in human airway trees. Eur Respir J 2015; 46: Suppl. 59, PA758.

14 Pompe E, De Jong P, Van Rikxoort E, et al. Bone density is associated with emphysema and air trapping on CT in smokers. Eur Respir J 2015; 46: Suppl. 59, PA3754.

15 Schönfeld C, Cebotari S, Hinrichs J, et al. MRI-derived regional pulmonary perfusion and cardiac function for monitoring patients with chronic thromboembolic pulmonary hypertension before and after pulmonary endarterectomy. Eur Respir J 2015; 46: Suppl. 59, OA4990.

16 Ema R, Sugiura T, Kawata N, et al. Ratio of pulmonary arterial to aortic diameter and right to left ventricular diameter associate with poor outcome in medically-treated chronic thromboembolic pulmonary hypertension. Eur Respir J 2015; 46: Suppl. 59, PA3747.

17 Bakker E, Ninaber M, Stolk J, et al. Pulmonary artery dilation and increased lung density in systemic sclerosis Eur Respir J 2015; 46: Suppl. 59, PA3743.

18 Brochhausen C, Schmitt C, Schmitt VH, et al. Comparative studies on bronchuswall-thickness by histologic and computed tomographic measurements of porcine lungs. Eur Respir J 2015; 46: Suppl. 59, PA3737.

19 Velde VG, Poelmans J, De Langhe E, et al. Longitudinal micro-CT of preclinical models of lung disease provides biomarkers of disease and therapy that reveal compensatory changes in lung volume. Eur Respir J 2015; 46: Suppl. 59, PA3748.

20 Chan H-F, Parra-Robles J, Brightling C, et al. Lobar comparison of CT densitometry and ${ }^{3} \mathrm{He}$ diffusion MRI models of lung microstructure in asthmatics. Eur Respir J 2015; 46: Suppl. 59, OA4991.

21 Crombag L, Stigt J, Dooms C, et al. Added value of EUS-B to EBUS for lung cancer staging. Eur Respir J 2015; 46 Suppl. 59, PA772.

22 Vilmann P, Clementsen PF, Colella S, et al. Combined endobronchial and oesophageal endosonography for the diagnosis and staging of lung cancer. Eur Respir J 2015; 46: 40-60.

23 Hardavella G, McCann C, Succony L, et al. Satisfaction of patients and operators from sedation in EBUS-TBNA the "SEDATE" study. Eur Respir J 2015; 46: Suppl. 59, PA326.

24 Laursen CB, Davidsen JR, Graumann O, et al. Ultrasound guided transthoracic biopsy performed by respiratory physicians: diagnostic yield and complications. Eur Respir J 2015; 46: Suppl. 59, PA2205.

25 Raghu G, Rochwerg B, Zhang Y, et al. An Official ATS/ERS/JRS/ALAT clinical practice guideline: treatment of idiopathic pulmonary fibrosis. An update of the 2011 clinical practice guideline. Am J Respir Crit Care Med 2015; 192: e3-e19.

26 Cottin V, Maher TM, Azuma A, et al. Pirfenidone post-authorization safety registry (PASSPORT) update. Eur Respir J 2015; 46: Suppl. 59, OA4500.

27 Crestani B, Ogura T, Pelling K, et al. Interim analysis of nintedanib in an open-label extension of the INPULSIS trials (INPULSIS ${ }^{-O N}$ ). Eur Respir J 2015; 46: Suppl. 59, OA4495.

28 Maher TM, Flaherty KR, Noble PW, et al. Effect of baseline FVC on lung function decline with nintedanib in patients with IPF. Eur Respir J 2015; 46: Suppl. 59, OA4499. 
29 Moore BB, Moore TA. Viruses in idiopathic pulmonary fibrosis. Etiology and exacerbation. Ann Am Thorac Soc 2015; 12: Suppl. 2, S186-S192.

30 Molyneaux P, Cookson W, Moffatt M, et al. Changes in the respiratory microbiome during acute exacerbations of idiopathic pulmonary fibrosis. Eur Respir J 2015; 46: Suppl. 59, OA3506.

31 Fischer A, Antoniou KM, Brown KK, et al. An official European Respiratory Society/American Thoracic Society research statement: interstitial pneumonia with autoimmune features. Eur Respir J 2015; 46: $976-987$.

32 Pereira DAS, Dias OM, Araujo MS, et al. What if my lung-dominant connective tissue disease (LD-CTD) patient eventually met criteria for a definite CTD: the role of prognosis! Eur Respir J 2015; 46: Suppl. 59, PA3799.

33 Herrera M, Luque L, Culebras M, et al. Diagnostic yield of transbronchial criobiopsia in transplant patients and patients with suspected ILD. Eur Respir J 2015; 46: Suppl. 59, PA2193.

34 López V, López X, Herrero S, et al. Complications of transbronchial cryobiopsy in insterticial lung diseases. Eur Respir J 2015; 46: Suppl. 59, PA2194.

35 Boland $\mathrm{M}$, Tsiachristas $\mathrm{A}$, Chavannes $\mathrm{N}$, et al. Does registration of performance indicators improve health outcomes in COPD? Eur Respir J 2015; 46: Suppl. 59, OA3286.

36 Harries T, Jackson K, White P. COPD readmissions in an urban environment: health service factors. Eur Respir J 2015; 46: Suppl. 59, OA3291.

37 Jordan R, Adab P, Sitch A, et al. TargetCOPD: a pragmatic randomised controlled trial of targeted case finding for COPD versus routine practice in primary care. Eur Respir J 2015; 46: Suppl. 59, OA3285.

38 Fastenau A, Van Schayck O, Winkens B, et al. Effectiveness of a physical exercise training programme COPD in primary care: a randomized controlled trial. Eur Respir J 2015; 46: Suppl. 59, OA3287.

39 Buni H, Jordan R, Adab P, et al. COPD over diagnosis in the UK. Eur Respir J 2015; 46: Suppl. 59 , OA3288.

40 Josephs L, Johnson M, Orlando R, et al. An observational study of age-related smoking status in COPD patients stratified by severity of airflow obstruction. Eur Respir J 2015; 46: Suppl. 59, OA4788.

41 Romberg K, Wieloch M, Kåregård M, et al. One year with certified asthma and COPD-clinics in Skåne, Sweden. Eur Respir J 2015; 46: Suppl. 59, OA4789.

42 Van Boven J, Román-Rodríguez M, Palmer J, et al. Prevalence of comorbidities in patients with asthma-COPD overlap syndrome (ACOS) in primary care. Eur Respir J 2015; 46: Suppl. 59, OA4786.

43 Klooster K, Ten Hacken NH, Hartman JE, et al. Endobronchial valve treatment versus standard medical care in patients with emphysema without interlobar collateral ventilation. Eur Respir J 2015; 46: Suppl. 59 , PA792.

44 Klooster K, Ten Hacken NH, Hartman JE, et al. Endobronchial valves for emphysema without intrelobar collatera ventilation. N Engl J Med 2015; 373: 2325-2335.

45 Valipour A, Asadi S, Hutya V, et al. Intrabronchial valve treatment in patients with severe heterogeneous emphysema and intact interlobar fissures. Eur Respir J 2015; 46: Suppl. 59, PA809.

46 Kontogianni K, Gerovasili V, Schuhmann M, et al. Endoscopic lung volume reduction (ELVR) treatment for patients with severe heterogeneous emphysema and bilateral incomplete fissures. Effectiveness and complications of coils' implantation at 90 days follow up. Eur Respir J 2015; 46: Suppl. 59, PA796.

47 Herth FJF, Valipour A, Eberhardt R, et al. Treating the most diseased segments in patients with severe emphysema: 6 month results from the STEP-UP randomized controlled trial (RCT). Eur Respir J 2015; 46: Suppl. 59, PA4864.

48 Slebos D-J, Klooster K, Koegelenberg C, et al. Two-year safety of targeted lung denervation in patients with moderate to severe COPD. Eur Respir J 2015; 46: Suppl. 59, PA798.

49 Koegelenberg C, Theron J, Slebos D-J, et al. Additive effect of targeted lung denervation plus drug in patients with COPD. Eur Respir J 2015; 46: Suppl. 59, PA3963.

50 Facciolongo N, Di Stefano A, Pietrini V, et al. The effect of bronchial thermoplasty on nerve C-fibers and inflammatory cells in patients with severe asthma. Eur Respir J 2015; 46: Suppl. 59, OA1762. 